\title{
Period-Dependent Survival Benefit of Percutaneous Microwave Ablation for Hepatocellular Carcinoma: A 12-Year Real-World, Multicentric Experience
}

\author{
Jie $\mathrm{Yu}^{\mathrm{a}}$ Zhi-Gang Cheng ${ }^{\mathrm{a}}$ Zhi-Yu Han ${ }^{\mathrm{a}}$ Fang-Yi Liu ${ }^{\mathrm{a}}$ Rong-Qin Zheng ${ }^{\mathrm{b}}$ \\ Wen Cheng ${ }^{c}$ Qiang Weid ${ }^{d}$ Song-Yuan Yu ${ }^{e}$ Qin-ying Lif ${ }^{f}$ Guang-zhi He ${ }^{g}$ \\ Yan-chun Luo ${ }^{a}$ Xiao-Ling Yu ${ }^{a}$ Ping Liang ${ }^{a}$ \\ aDepartment of Interventional Ultrasound, PLA Medical College\& 5th Medical Center of Chinese PLA General \\ Hospital, Beijing, China; 'bepartment of Medical Ultrasound, Third Affiliated Hospital of Sun Yat-Sen University, \\ Guangzhou, China; 'Department of Ultrasound, Harbin Medical University Cancer Hospital, Harbin City, China; \\ ${ }^{\mathrm{d}}$ Department of Ultrasound, The Second Hospital of Nanjing, Nangjing, China; ${ }^{\mathrm{D}}$ Department of Wuhan University \\ of Science and Technology, Tianyou Hospital, Wuhan, China; 'Department of Ultrasound, Puyang Hospital of \\ Traditional Chinese Medicine of Henan Province, Puyang, China; ${ }^{9}$ Department of Ultrasound, University of Chinese \\ Academy of Sciences Shenzhen Hospital, Shenzhen, China
}

\section{Keywords}

Hepatocellular carcinoma - Microwave ablation .

Period-dependent survival benefit · Real-world data

\begin{abstract}
Introduction: Although microwave ablation (MWA) is a promising technique for hepatocellular carcinoma (HCC) treatment, its 10-year efficacy is unknown. Objective: The objective of the study was to assess whether the advances in MWA for HCC translated into a real-world survival benefit. Methods: This retrospective study included 2,354 patients with Barcelona Clinic Liver Cancer (BCLC) stage 0 to B from 5 hospitals, with at least 2 years of follow-up for all the patients. Recurrence and survival were analyzed using the Kaplan-Meier method with time-period stratification. Results: A total of 5,326 HCCs (mean diameter, $2.9 \mathrm{~cm} \pm 1.2$ ) underwent 4,051 sessions of MWA with a median follow-up of 61.3 (0.6-169.5 range) months during 3 periods (2007-2010, 2011-2014, and 2015-2018). Technical success was achieved in 5,194 (97.5\%) tumors with significant improvement over
\end{abstract}

time, especially for $>3.0-\mathrm{cm} \mathrm{HCC}(p<0.001)$. Local tumor progression (LTP) showed no period-dependent advance, with $>3.0-\mathrm{cm} \mathrm{HCC}$ and perivascular location being the risk factors for LTP. The median intrahepatic metastasis time was 27.6 (95\% confidence interval [Cl]:25.2-28.8) months, with 5- and 10 -year occurrence rates of $68.8 \%$ and $79.4 \%$, respectively. The 5 - and 10 -year overall survivals were $63.9 \%$ and $41.1 \%$, respectively, and $B C L C$ stage $0, A$, and all $B$ patients showed an observable survival improvement over time $(p<0.001)$. The median disease-free survival time increased from 19.4 (95\% Cl: $16.5-22.6)$ months in $2007-2010$ to 28.1 (95\% Cl: 25.9-32.3) months in 2015-2018. The improved survival for early recurrent ( $\leq 2$ years) patients was period-dependent, as verified by Cox regression analyses. The major complications rate per procedure was $3.0 \%(122 / 4,051)$. Conclusions: These real-world data show that MWA provided an upward trend in survival for $\mathrm{HCC}$ patients with BCLC stage $0-B$ over a 12-year follow-up period. An encouraging clear survival benefit in early recurrent patients was also observed.

(C) 2022 The Author(s)

Published by S. Karger AG, Basel
(C) 2022 The Author(s)

Published by S. Karger AG, Basel

This is an Open Access article licensed under the Creative Commons Attribution-NonCommercial-4.0 International License (CC BY-NC) (http://www.karger.com/Services/OpenAccessLicense), applicable to the online version of the article only. Usage and distribution for commercial purposes requires written permission.
Correspondence to:

Ping Liang, liangping301@ hotmail.com 


\section{Introduction}

Hepatocellular carcinoma (HCC) is a leading cause of cancer-related deaths worldwide, and it is expected to rise in incidence [1]. Because $80 \%$ of HCC patients are not candidates for liver resection and transplantation [2], various nonsurgical locoregional interventional treatments have been developed over the past 20 years [3]. Among those, image-guided percutaneous ablation has been considered a potentially curative treatment for patients with early-stage HCC, particularly for those who cannot endure surgery or had repeated recurrences $[2,3]$. The most commonly used modalities are radiofrequency ablation (RFA) and microwave ablation (MWA). MWA has become popular since its first clinical study in 1994 [4], with the advantage of having higher thermal efficiency for the primary active heating characteristics than RFA [5-7]. More importantly, two recent randomized controlled clinical trials showed that MWA is more efficacious than RFA for eradicating larger tumors of size $3-5 \mathrm{~cm}$ and requires less ablation time $[8,9]$. Therefore, MWA has been a topic of interest in the field of minimally invasive treatment for HCC, especially for larger HCCs and elderly patients with comorbidities and who cannot tolerate treatment lasting a relatively long time.

With the progress in equipment and technique in recent years, MWA has achieved progress beyond its initial use for very early-stage HCC as included in the international guidelines [10]. Increasing evidence has shown the effect of MWA in treating larger and multiple HCC lesions adjacent to the vital organs since the early 2010s [11-14]. Among the various clinical studies of MWA until recently, there has been no reliable evidence on the relatively long-term outcome of MWA for HCC [15-18]. Furthermore, it is unknown whether and to what extent the improvement in MWA for HCC reported by clinical studies has been translated into clinical practice for the intermediate-stage patients. Thus, a sufficiently large evidence-based analysis of MWA for HCC is needed.

The aims of our study were to evaluate the12-year follow-up results of MWA for the treatment of HCC with Barcelona Clinic Liver Cancer (BCLC) stage 0, A, or B with consecutive case series from 5 medical centers. To our knowledge, this study analyzed the largest sample of percutaneous MWA treatments for HCC with the largest duration of long-term efficacy evaluation.

\section{Materials and Methods}

This cohort study was a retrospective analysis of a database collected from consecutive HCC patients who underwent MWA in five Chinese centers. Written informed consent for MWA procedures and the use of data for research purposes were obtained from each patient before each MWA procedure. The study is exempt from ethical committee approval due to its retrospective nature.

\section{Population and Data Collection}

We reviewed the departmental database of MWA procedures and retrieved the recorded data between January 2007 and December 2018. A total of 4,051 ultrasound (US)-guided percutaneous MWA sessions for 5,326 HCC tumors in 2,354 patients who had more than 2 years of follow-up after the MWA were analyzed in this study. Of these, 953 tumors (953/5,326, 17.9\%) were diagnosed as HCC using a US-guided core needle biopsy. The remaining 4,373 tumors $(4,373 / 5,326,82.1 \%)$ were diagnosed as HCC based on the clinical criteria from the international guidelines (online suppl. material 1; for all online suppl. material, see www. karger.com/doi/10.1159/000522134) for diagnosis of HCC prior to the MWA procedures [19-21].

The inclusion criteria for the patient enrollment in this study were as follows: (1) all HCC nodules $\leq 5 \mathrm{~cm}$ in maximum diameter; (2) $\leq 5$ HCC nodules in number; $(3) \leq 2$ HCC nodules if each maximum diameter $>3 \mathrm{~cm}$; (4) absence of portal venous and bile duct cancer embolus and no extrahepatic metastasis (EM) before MWA; (5) Child-Pugh class A or B; (6) prothrombin time ratio $>50 \%$ (prothrombin time with an international normalized ratio $<1.7$ ) and platelet count $>40 \times 10^{9} / \mathrm{L}$; and (7) no obvious ascites next to the puncture site of the liver. The decision to perform MWA was made by consensus of an interdisciplinary discussion, including hepatobiliary surgeons, oncologists, radiologists, and radiation therapists. In addition, the technical feasibility of percutaneous MWA was assessed by at least two radiologists who would perform the procedure. The data were provided by the clinicians using the standardized forms comprising the patients' age, sex, tumor size, number, and location, Child-Pugh classification, BCLC stage, clinically significant portal hypertension (online suppl. material 2), comorbidities, and cause of cirrhosis along with other characteristics such as initial disease, liver function test, antiviral therapy, and anticancer therapies received.

\section{MWA Procedures}

All MWA procedures were performed percutaneously under US guidance (Signature 7.2, Acuson Sequoia 512; Siemens Medical Solutions, Mountain View, CA, USA or LOGIQ E9; GE Medical Systems US \& Primary Care Diagnostics, Wauwatosa, WC, USA). MWA procedures were performed as previously reported [22] on an in-patient basis by 2 radiologists at a time out of a pool of 9 radiologists (L.P., Y.X.L., C.Z.G., H.Z.Y., Y.J., L.F.Y., Z.R.Q., C.W., and W.Q.) from 5 centers who had more than 10 years of experience with MWA. Artificial pleural effusion for tumors in the hepatic dome and artificial ascites for tumors adjacent to the gastrointestinal tract have been used since 2008 [11,23]. Following sedatives and local anesthesia administration, one or two 15-gauge cooled-tip antennae (Kangyou Medical, Nanjing, China) were inserted into the tumor. Detailed types of MWA generator and antennae at the five centers are summarized in online supplementary Table S1. Microwave energy of 40-60 W was delivered for 3-10 
min for each application. One antenna was used for tumors $<2.0$ $\mathrm{cm}$, and two antennae were used simultaneously for tumors $\geq 2.0$ $\mathrm{cm}$. The applicators were repeatedly inserted into different sites of the tumors, if necessary, to ensure that the entire tumor could be enveloped by the estimated ablation volume assessed by intra-procedure contrast-enhanced US. The target MWA endpoint was an ablative margin of at least $0.5-1.0 \mathrm{~cm}$ for tumors in a safe location, complete ablation, and less than a $0.5-\mathrm{cm}$ margin for tumors in subcapsular or perivascular location (online suppl. material 3).

\section{Follow-Up}

For early evaluation of the completeness of the ablation and for identification of possible complications, such as bleeding or fluid accumulation, contrast-enhanced US $(n=2,354,100 \%)$ combined with either magnetic resonance imaging $(n=1,506,64.0 \%)$ or computed tomography ( $n=848,36.0 \%)$ was performed within 72 $\mathrm{h}$ after MWA. Another percutaneous MWA was primarily chosen when a residual tumor was detected, unless MWA was technically unfeasible. If the ablated tumor was completely necrotic with sufficient ablative margin, the treatment was regarded as a technical success (TS), and a follow-up observation was performed 1 month later. A follow-up was repeated 3 months later and then at 6-month intervals until death. If local tumor progression (LTP) or intrahepatic distant metastasis (IDM) was observed during subsequent follow-up visits, an additional MWA was performed within a month after new lesions were detected, if possible. Chest radiographs and other appropriate examinations were performed for the detection of EM.

\section{Definitions of Ablation Terminology and Index of Therapeutic} Efficacy

Definitions are based on the standardization by the International Working Group on Image-Guided Tumor Ablation [24]. The terminologies, including session, treatment, TS, LTP, IDM, EM, disease-free survival (DFS), cancer-specific survival (CSS), and overall survival (OS), are described in online supplementary material 4. Complication classification was based on Clavien Grade [25], with the major complications including Clavien Grade III-V. Local therapeutic efficacy, including TS and LTP, was assessed on a tumor basis. IDM, EM, DFS, CSS, and OS were evaluated on a per-patient basis.

\section{Statistical Analysis}

Descriptive data are presented using numbers and percentages, mean and standard deviation, and median and interquartile range. The comparison of continuous variables between more than two groups was performed using the Kruskal Wallis test; the MannWhitney U test was employed for two groups. To analyze the distribution of categorical variables between two groups, a $\chi^{2}$ test was used. The cumulative rates for each type of metastasis and survival were estimated with the Kaplan-Meier method. Independent prognostic factors for LTP, IDM, EM, and survival were assessed using the multivariate Cox proportional hazard model. Two models were used to analyze the association between death and recurrence with potential prognostic factors from multivariable Cox analysis for OS, with model 1 being unadjusted and model 2 adjusting the factors. The risks of OS were analyzed using Fine-andGray competing risk models, with death from non-HCC causes considered a competing event. Missing values were imputed using multiple methods. All of the variables with $p$ values $<0.05$ in uni-

Microwave Ablation of Hepatocellular Carcinoma variate analyses were included in the multivariable models. To examine the potential influence of the therapeutic progress with the year of MWA on the survival of HCC patients, three periods (2007-2010, 2011-2014, and 2015-2018) were defined. OS, CSS, and DFS curves of different periods were compared with the logrank test. Results are presented as hazard ratios (HRs) with $95 \%$ confidence intervals (CIs). All analyses were performed using $\mathrm{R}$ packages (http://www.R-project.org) and EmpowerStats software (http://www.empowerstats.com; X\&Y Solutions Inc., Boston, MA, USA).

\section{Results}

\section{Patient and Tumor Characteristics}

We performed a total of 4,051 MWA sessions for the 2,354 HCC patients (male:female ratio, 1,923:431; mean age, $57.4 \pm 10.9$ years; age range, $24-91$ years) with 5,326 HCCs between years 2007 and 2018 (Fig. 1), stratified by three time-periods based on the date of initial MWA (2007-2010, 2011-2014, 2015-2018). The baseline characteristics of censored participants were not significantly different from those of enrolled patients (online suppl. Table S2). Ninety-two patients underwent a second session for the residual tumor detected by contrast-enhanced imaging within $72 \mathrm{~h}$ after the first MWA. The gradual increase in the numbers of MWA after the year 2010 reflects the improvement of the technique. The baseline clinical characteristics of all of the HCC patients are shown in Table 1 . The average age of patients and tumor number were stable among the three periods. In all, 995 patients (42.3\%) were $\geq 60$ years old. A total of 769 (32.7\%) patients had tumors with BCLC stage B; 816 (34.7\%) patients were at high risk for resection for comorbidities. Among the 5,326 tumors, 2,218 (41.6\%) were adjacent to the gastrointestinal tract, hepatic hilum, diaphragm, $\geq 3$ $\mathrm{mm}$ vessel, pericardium, and cholecyst subcapsular or perivascular location.

\section{Ablation Parameters and TS}

The TS for the total cohort was $97.5 \%(5,194 / 5,326)$. For patients with $>3.0-\mathrm{cm}$ HCC, the TS was inferior to that of patients with $\leq 3.0$-cm lesions $(p<0.001)$, and ablation sessions, time, and power were significantly more than those in patients with $\leq 3.0-\mathrm{cm}$ lesions $(p<0.001$; Table 2). In the latest period, the TS improved significantly compared to the previous two periods, especially for $>3.0-\mathrm{cm} \mathrm{HCC}(p<0.001)$. Ablation power gradually increased, and ablation sessions gradually decreased with a correlative decrease of the hospitalization after MWA over time for both tumor size subgroups (Table 2). 


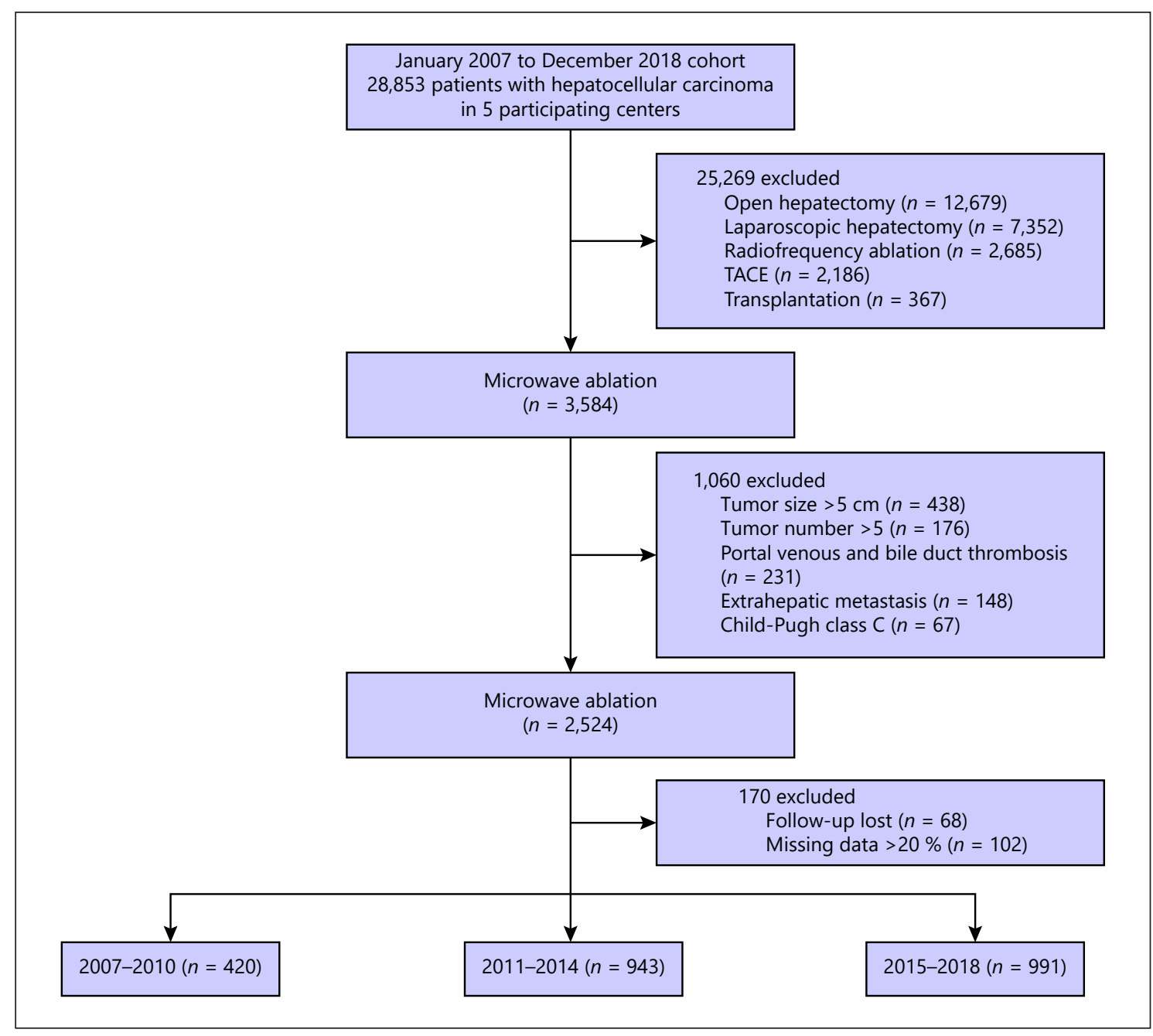

Fig. 1. Study flowchart.

\section{Tumor Progression}

Tumor progression comprised LTP, IDM, and EM based on new lesion location and was classified as early recurrence (ER, $\leq 2$ years after MWA) and late recurrence (LR, > 2 years after MWA) based on new lesion onset time. Among the 1,546 patients with tumor recurrence, $1,192(77.1 \%)$ received iterative MWA treatments. A total of 1,569 patients underwent MWA treatment once, 437 twice, 148 thrice, 84 four times, 45 five times, 27 six times, 18 seven times, 13 eight times, 6 nine times, 5 ten times, and 2 eleven times. MWA and other treatments such as TACE or systemic treatment for recurrence are summarized in online supplementary Table S3 and online supplementary Figure S1. The rates of no recurrence (NR), ER, and LR were $34.3 \%, 47.7 \%$, and $18.0 \%$, respectively. Cumulative LTP, IDM, and EM rates among the three periods are shown in Figure 2 and online supplementary Table S4. The 1-, 3-, 5-, and 10-year LTP rates in patients, overall, were $5.4 \%, 9.6 \%, 10.3 \%$, and $12.2 \%$, respectively. There was no significant LTP difference between tumors in safe and subcapsular locations. However, the perivascular tumors achieved inferior LTP compared to tumors in a safe location, and 3.0-5.0- $\mathrm{cm}$ tumors achieved inferior LTP compared to $\leq 3.0$-cm tumors (Fig.2b, c, online suppl. Table S4). LTP did not show the improvement trend over time. However, IDM and EM showed a difference when taking the time-period at MWA into account (Fig. 2a, d, e). Considering all patients, the median IDM, ER, and LR time was 27.6 (95\% CI: 25.2-28.8) months, $9.0(8.4,9.7)$ months, and $66.0(61.3,71.6)$ months, respectively. 
Table 1. Patient and tumor characteristics $(2007-2018, n=2354)$

\begin{tabular}{|c|c|c|c|c|}
\hline \multirow[t]{2}{*}{ Variable } & \multicolumn{4}{|l|}{ Value } \\
\hline & $\begin{array}{l}\text { total } \\
(n=2354)\end{array}$ & $\begin{array}{l}2007-2010 \\
(n=420)\end{array}$ & $\begin{array}{l}2011-2014 \\
(n=943)\end{array}$ & $\begin{array}{l}2015-2018 \\
(n=991)\end{array}$ \\
\hline \multicolumn{5}{|l|}{ Sex, $n(\%)$} \\
\hline Male & $1,923(81.7)$ & $349(83.1)$ & $768(81.4)$ & $806(81.3)$ \\
\hline Female & $431(18.3)$ & $71(16.9)$ & $175(18.6)$ & $185(18.7)$ \\
\hline Age, years, mean $\pm S D$ & $57.4 \pm 10.9$ & $57.3 \pm 10.8$ & $57.2 \pm 10.8$ & $57.6 \pm 11.0$ \\
\hline$<60$, years, $n(\%)$ & $1,359(57.7)$ & $251(59.8)$ & $551(58.4)$ & $557(56.2)$ \\
\hline$\geq 60$, years, $n(\%)$ & $995(42.3)$ & $169(40.2)$ & $392(41.6)$ & $434(43.8)$ \\
\hline Charlson comorbidity index, median (IQR) & $2.0(1.0-3.0)$ & $2.0(1.0-3.0)$ & $2.0(1.0-3.0)$ & $2.0(1.0-3.0)$ \\
\hline \multicolumn{5}{|l|}{ Tumors, $n(\%)$} \\
\hline Single & $1,652(70.2)$ & $280(66.7)$ & $677(71.8)$ & $695(70.1)$ \\
\hline $2 / 3$ & $622(26.4)$ & $125(29.8)$ & $237(25.1)$ & $260(26.2)$ \\
\hline $4 / 5$ & $80(3.4)$ & $15(3.6)$ & $29(3.0)$ & $36(3.6)$ \\
\hline Tumor size, $\mathrm{cm}$, mean $\pm \mathrm{SD}$ & $2.5 \pm 1.0$ & $2.6 \pm 1.0$ & $2.6 \pm 0.9$ & $2.5 \pm 1.0$ \\
\hline$\leq 3.0 \mathrm{~cm}, n(\%)$ & $1,668(70.9)$ & $282(67.1)$ & $665(70.5)$ & $721(72.8)$ \\
\hline $3.1-5.0 \mathrm{~cm}, n(\%)$ & $686(29.1)$ & $138(32.9)$ & $278(29.5)$ & $270(27.2)$ \\
\hline \multicolumn{5}{|l|}{ Tumor location, $n$ (\%) } \\
\hline Safe & $3,108(58.4)$ & $356(46.3)$ & $1,256(54.8)$ & $1,495(65.8)$ \\
\hline Subcapsular & $1,656(31.1)$ & $302(39.3)$ & $787(34.4)$ & $567(25.0)$ \\
\hline Perivascular & $562(10.5)$ & $111(14.4)$ & $243(10.8)$ & $208(9.2)$ \\
\hline \multicolumn{5}{|l|}{ Cause of cirrhosis, $n(\%)$} \\
\hline Hepatitis B virus & $1,762(74.9)$ & $309(73.6)$ & $713(75.6)$ & $740(74.7)$ \\
\hline Hepatitis $C$ virus & $207(8.8)$ & $57(13.6)$ & $67(7.1)$ & $83(8.4)$ \\
\hline Hepatitis $B+C$ virus & $30(1.3)$ & $4(1.0)$ & $13(1.4)$ & $13(1.3)$ \\
\hline Alcohol abuse & $24(1.0)$ & $2(0.5)$ & $9(1.0)$ & $13(1.3)$ \\
\hline MAFLD & $108(4.6)$ & $15(3.6)$ & $45(4.8)$ & $48(4.8)$ \\
\hline Undetermined & $223(9.5)$ & $34(8.1)$ & $94(10.0)$ & $95(9.6)$ \\
\hline \multicolumn{5}{|l|}{ Antiviral therapy, $n$ (\%) } \\
\hline Yes & $1,776(87.1)$ & $303(81.2)$ & $715(88.3)$ & $768(88.6)$ \\
\hline No & $262(12.9)$ & $70(18.8)$ & $95(11.7)$ & $87(11.4)$ \\
\hline \multicolumn{5}{|c|}{ Clinically significant portal hypertension, $n(\%)$} \\
\hline Yes & $806(34.2)$ & $125(29.8)$ & $325(34.5)$ & $356(35.9)$ \\
\hline No & $1,548(65.8)$ & $295(70.2)$ & $618(65.5)$ & $635(64.1)$ \\
\hline \multicolumn{5}{|l|}{ Child-Pugh classification, $n$ (\%) } \\
\hline A & $2262(96.1)$ & $389(92.6)$ & $918(97.3)$ & $955(96.4)$ \\
\hline $\mathrm{B}$ & $92(3.9)$ & $31(7.4)$ & $25(2.7)$ & $36(3.6)$ \\
\hline \multicolumn{5}{|l|}{ BCLC stage, $n(\%)$} \\
\hline 0 & $626(26.6)$ & $116(27.6)$ & $214(22.7)$ & $296(29.9)$ \\
\hline$A$ & $959(40.7)$ & $159(37.9)$ & $415(44.0)$ & $385(38.8)$ \\
\hline $\mathrm{B}$ & $769(32.7)$ & $145(34.5)$ & $314(33.3)$ & $310(31.3)$ \\
\hline Initial HCC, $n$ (\%) & $1,259(53.5)$ & $212(50.5)$ & $518(54.9)$ & $529(53.4)$ \\
\hline \multicolumn{5}{|l|}{ Method of diagnosis, $n$ (\%) } \\
\hline Biopsy & $700(29.7)$ & $161(38.3)$ & $198(21.0)$ & $341(34.4)$ \\
\hline $\mathrm{CT} / \mathrm{MRI}+\mathrm{AFP}$ & $1,654(70.3)$ & $259(61.7)$ & $745(79.0)$ & $650(65.6)$ \\
\hline \multicolumn{5}{|l|}{ Serum AFP, ng/mL, $n(\%)$} \\
\hline$\leq 20$ & $1,474(62.6)$ & $283(67.4)$ & $576(61.1)$ & $615(62.1)$ \\
\hline $20.1-99.9$ & $338(14.4)$ & $56(13.3)$ & $141(15.0)$ & $141(14.2)$ \\
\hline$\geq 100$ & $542(23.0)$ & $81(19.3)$ & $226(24.0)$ & $235(23.7)$ \\
\hline Total bilirubin, $\mathrm{mg} / \mathrm{dL}$, mean $\pm \mathrm{SD}$ & $1.9 \pm 1.1$ & $2.0 \pm 1.0$ & $1.9 \pm 1.2$ & $1.8 \pm 1.0$ \\
\hline Albumin, g/L, mean $\pm S D$ & $39.5 \pm 4.6$ & $38.9 \pm 2.8$ & $39.6 \pm 5.1$ & $39.7 \pm 4.8$ \\
\hline Creatinine, $\mathrm{mg} / \mathrm{dL}$, mean $\pm \mathrm{SD}$ & $75.3 \pm 36.2$ & $74.7 \pm 20.2$ & $72.9 \pm 19.2$ & $77.7 \pm 50.3$ \\
\hline Neutrophil to lymphocyte ratio, median (IQR) & $1.7(1.3-2.5)$ & $2.1(1.4-3.2)$ & $1.7(1.2-2.3)$ & $1.8(1.3-2.5)$ \\
\hline International normalized ratio, mean \pm SD & $1.1 \pm 0.1$ & $1.1 \pm 0.1$ & $1.1 \pm 0.2$ & $1.1 \pm 0.1$ \\
\hline $\mathrm{DCP}$, mean $\pm \mathrm{SD}$ & $14.3 \pm 1.9$ & $14.3 \pm 1.7$ & $14.0 \pm 2.1$ & $14.6 \pm 1.7$ \\
\hline MELD, median (IQR) & $5.1(3.1-7.2)$ & $5.5(3.4-7.5)$ & $5.5(3.4-7.5)$ & $5.1(3.1-7.3)$ \\
\hline
\end{tabular}

MAFLD, metabolic associated fatty liver disease; HCC, hepatocellular carcinoma; AFP, a-fetoprotein; CT, computed tomography; MRI, magnetic resonance image; DCP, prothrombin time; MELD, model for end-stage liver disease; IQR, interquartile range. 
Table 2. Ablation parameters

\begin{tabular}{|c|c|c|c|c|c|}
\hline Characteristic* & $\begin{array}{l}\text { Total } \\
(n=5,326)\end{array}$ & $\begin{array}{l}2007-2010 \\
(n=770)\end{array}$ & $\begin{array}{l}2011-2014 \\
(n=2286)\end{array}$ & $\begin{array}{l}2015-2018 \\
(n=2270)\end{array}$ & $p$ value \\
\hline \multicolumn{6}{|l|}{$\mathrm{TS}, n(\%)$} \\
\hline$\leq 3.0 \mathrm{~cm}$ & 4,291 (98.3) & $582(98.0)$ & $1,861(98.1)$ & $1,848(98.6)$ & $<0.001$ \\
\hline $3.1-5.0 \mathrm{~cm}$ & $903(94.1)$ & $165(93.8)$ & $357(91.8)$ & $381(96.5)$ & $<0.001$ \\
\hline$p$ value & $<0.001$ & $<0.001$ & $<0.001$ & $<0.001$ & - \\
\hline \multicolumn{6}{|c|}{ Ablation session, mean $\pm S D$} \\
\hline$\leq 3.0 \mathrm{~cm}$ & $1.1 \pm 0.3$ & $1.2 \pm 0.4$ & $1.1 \pm 0.3$ & $1.0 \pm 0.2$ & $<0.001$ \\
\hline $3.1-5.0 \mathrm{~cm}$ & $1.2 \pm 0.4$ & $1.4 \pm 0.6$ & $1.2 \pm 0.5$ & $1.1 \pm 0.3$ & $<0.001$ \\
\hline$p$ value & $<0.001$ & $<0.001$ & $<0.001$ & $<0.001$ & - \\
\hline \multicolumn{6}{|c|}{ Hospitalization after MWA, day, mean \pm SD } \\
\hline$\leq 3.0 \mathrm{~cm}$ & $5.7 \pm 3.2$ & $6.2 \pm 4.4$ & $5.6 \pm 3.0$ & $5.7 \pm 2.7$ & $<0.001$ \\
\hline $3.1-5.0 \mathrm{~cm}$ & $7.0 \pm 4.2$ & $8.5 \pm 6.3$ & $6.5 \pm 3.8$ & $6.4 \pm 2.9$ & $<0.001$ \\
\hline$p$ value & $<0.001$ & $<0.001$ & $<0.001$ & $<0.001$ & - \\
\hline \multicolumn{6}{|c|}{ Ablation time, min, mean $\pm S D$} \\
\hline$\leq 3.0 \mathrm{~cm}$ & $6.4 \pm 3.3$ & $7.4 \pm 3.6$ & $6.0 \pm 2.9$ & $6.4 \pm 3.5$ & $<0.001$ \\
\hline $3.1-5.0 \mathrm{~cm}$ & $11.5 \pm 6.9$ & $12.2 \pm 7.1$ & $10.1 \pm 5.7$ & $12.7 \pm 7.7$ & $<0.001$ \\
\hline$p$ value & $<0.001$ & $<0.001$ & $<0.001$ & $<0.001$ & - \\
\hline \multicolumn{6}{|c|}{ Ablation power, $\mathrm{W}$, mean $\pm \mathrm{SD}$} \\
\hline$\leq 3.0 \mathrm{~cm}$ & $51.5 \pm 3.8$ & $49.9 \pm 2.2$ & $50.6 \pm 2.8$ & $53.2 \pm 4.8$ & $<0.001$ \\
\hline $3.1-5.0 \mathrm{~cm}$ & $52.3 \pm 4.3$ & $50.5 \pm 2.7$ & $51.0 \pm 2.9$ & $54.7 \pm 5.1$ & $<0.001$ \\
\hline$p$ value & $<0.001$ & 0.01 & 0.02 & $<0.001$ & - \\
\hline
\end{tabular}

* Hospitalization after MWA was calculated based on the patients number, and ablation session and TS were calculated based on the tumor number.

\section{Long-Term Survival}

All of the patients who survived were followed up with for more than 2 years. By December 2020 (with a median follow-up of 61.3 months, a range of 0.6-169.5 months), 1,535 patients $(65.2 \%)$ were alive, and $819(34.8 \%)$ died. The time of death after MWA ranged from 0.6 to 139.4 months with a median survival time of 86.1 (95\% CI: 81.2-97.2) months. HCC progression was the leading cause of death, claiming the lives of $613(74.8 \%)$ patients (online suppl. Table S5). Only $11.1 \%$ of the patients died of nonHCC-related causes. The 1-, 3-, 5-, 7-, and 10-year OS, CSS, and DFS rates of the total cohort, tumor stage stratification cohort, and recurrence time stratification cohort are summarized in online supplementary Table S6 and are shown in Figures 3 and 4 and online supplementary Figure S2. An improved outcome over time could be observed in OS, DFS, and CSS for all patients (Fig. 3a, 4a, $4 c)$. The late BCLC stage showed poor OS, DFS, and CSS than the early stage (Fig. 4b, d, online suppl. Fig. S2). The median DFS times increased from 19.4 (95\% CI: 16.522.6) months in 2007-2010 to 22.9 (95\% CI: 20.4-25.4) months in 2011-2014 and to 28.1 (95\% CI: 25.9-32.3) months in 2015-2018.
Based on the different time-period groups, a significant effect on OS improvement over time could be observed in the NR and ER cohorts (both $p<0.001$; Fig. 3b, c), although ER patients showed poorer survival compared with NR and LR patients (online suppl. Fig. S3). However, the OS did not improve in LR patients (Fig. 3d). The time-period-dependent OS and CSS advancement of NR and ER patients was also verified by the Cox proportional hazards regression model, which controlled for the age, tumor BCLC stage, initial HCC, serum alpha-fetoprotein (AFP level, albumin, and ablation period (Table 3). Although ER patients showed poorer survival compared with NR and LR patients (online suppl. Fig. S3), an improved OS overtime could be observed in ER patients (Fig. 3c). However, the OS did not improve in LR patients (Fig. 3d) regardless of a great MWA (online suppl. Fig. S7).

Fig. 2. a Analysis of LTP. b LTP between tumors in safe and subcapsular locations. c LTP between tumors in safe and perivascular locations. d LTP between tumors $\leq 3.0 \mathrm{~cm}$ and $>3.0 \mathrm{~cm}$. e Intrahepatic disease metastasis. $\mathbf{f}$ EM stratified by time-period of MWA.

(For figure see next page.) 

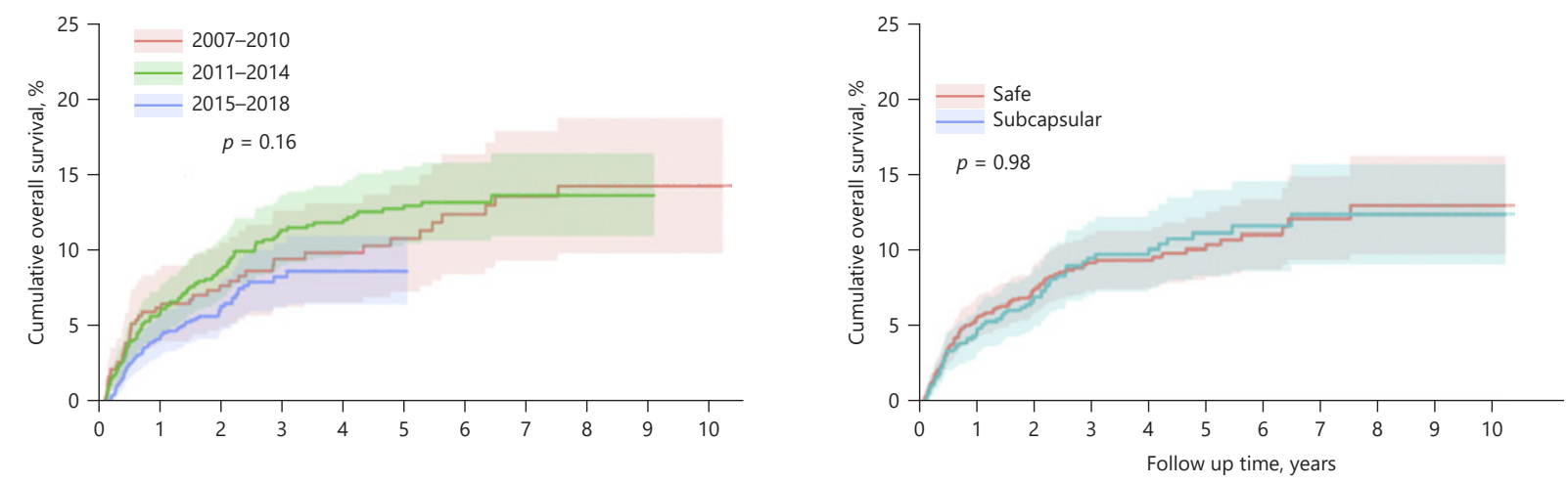

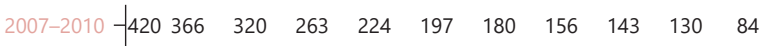
$\begin{array}{lllllllllll}2011-2014-942 & 852 & 721 & 624 & 559 & 494 & 294 & 137 & 38 & 2 & 0\end{array}$ 2015-2018 \begin{tabular}{|ccccccccccc}
991 & 894 & 598 & 281 & 108 & 4 & 0 & 0 & 0 & 0 & 0 \\
0 & 1 & 1 & 1 & 1 & 1 & 1 & 1 & 1 & 1 & 1
\end{tabular}

\section{a}

Follow up time, years

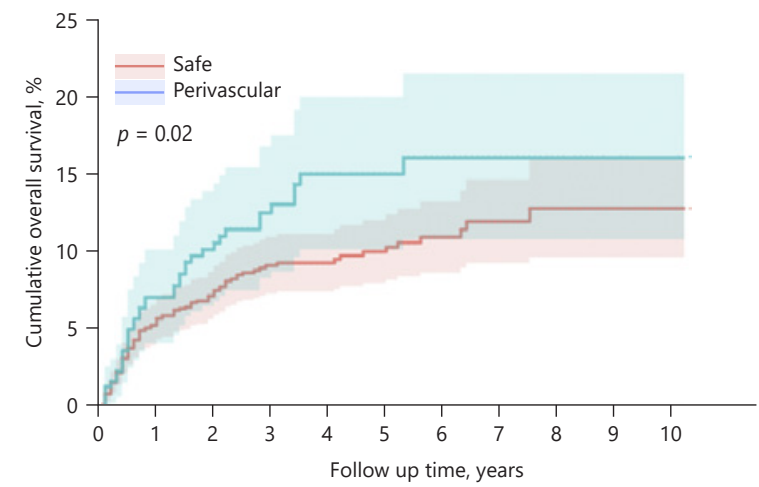

No.at risk

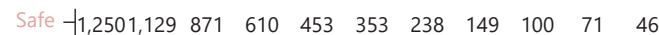
Perivascular \begin{tabular}{|cccccccccccc}
312 & 278 & 239 & 179 & 134 & 102 & 74 & 47 & 26 & 16 & 11 \\
\hline & 1 & 2 & 3 & 4 & 5 & 6 & 7 & 8 & 9 & 10
\end{tabular}

C

Follow up time, years

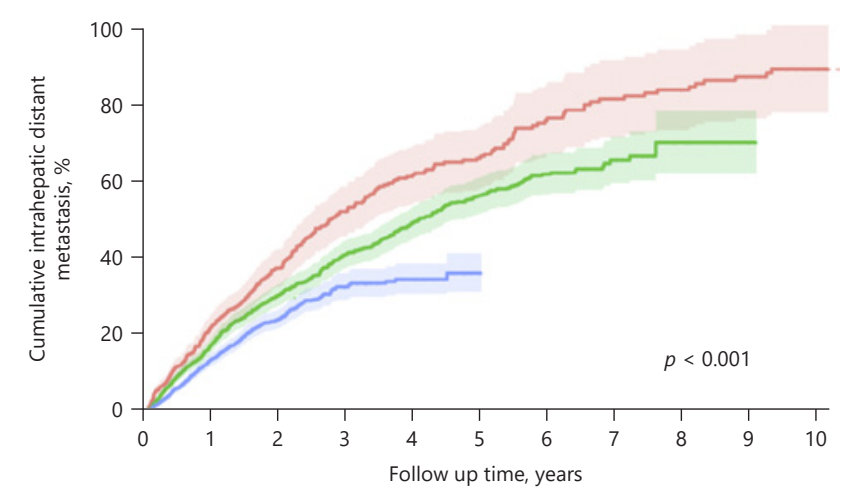

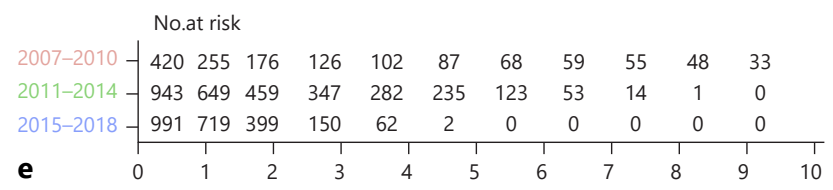



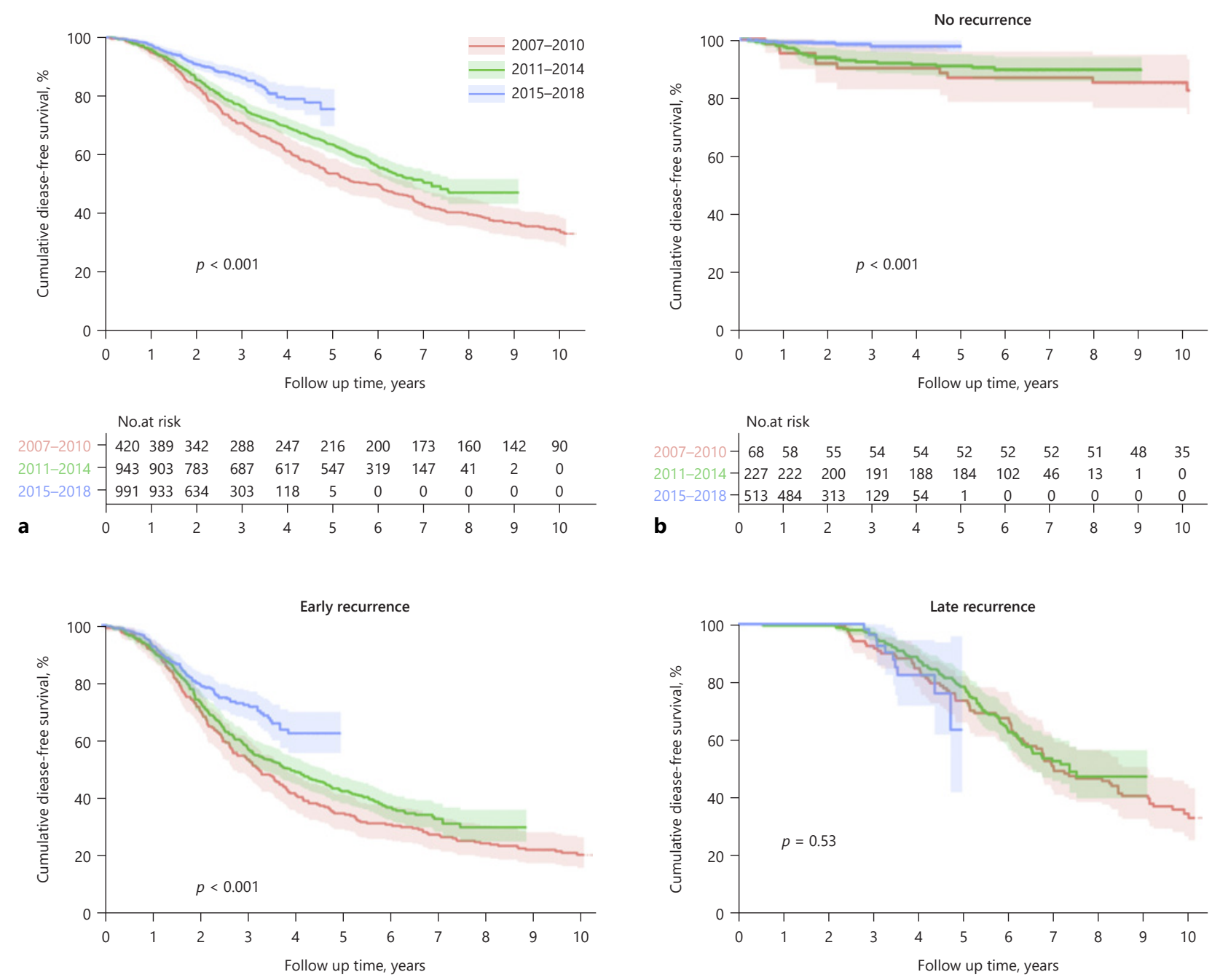

No.at risk

\begin{tabular}{|c|c|c|c|c|c|c|c|c|c|c|c|}
\hline $2007-2010-$ & 234 & 213 & 169 & 125 & 95 & 79 & 70 & 62 & 55 & 48 & 31 \\
\hline 2011-2014 & 476 & 442 & 344 & 267 & 220 & 183 & 109 & 46 & 14 & 0 & 0 \\
\hline 15-2018 & 413 & 384 & 256 & 124 & 46 & 4 & 0 & 0 & 0 & 0 & 0 \\
\hline c & 0 & 1 & 2 & 3 & 4 & 5 & $\begin{array}{l}1 \\
6\end{array}$ & 7 & 8 & 9 & 10 \\
\hline
\end{tabular}

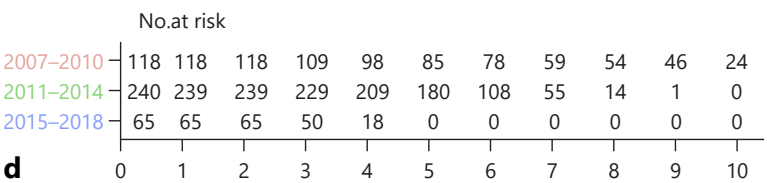

Fig. 3. a Analysis of OS. $\mathbf{b}$ OS of NR patients. $\mathbf{c}$ OS of ER patients. d OS of LR patients stratified by time-period of MWA according to the Kaplan-Meier method. OS, overall survival.

Multivariate Analysis for Survival

Each potential prognostic factor of multivariate analysis for OS, DFS, CSS, and tumor progression is summarized in online supplementary Tables S7-S14. The Cox regression model (online suppl. Table S8) and Fine-andGray competing risk models (online suppl. Table S9) concluded that the consistent risk factors for OS, including old age $(\mathrm{HR}=1.3, p=0.003)$, BCLC stage A $(\mathrm{HR}=1.4$, $p=0.002)$, BCLC stage $\mathrm{B}(\mathrm{HR}=2.7, p<0.001)$, recurrent $\mathrm{HCC}(\mathrm{HR}=1.7, p<0.001)$, serum AFP $\geq 100 \mathrm{ng} / \mathrm{mL}(\mathrm{HR}$ $=1.5, p<0.001)$, and albumin $<35 \mathrm{~g} / \mathrm{L}(\mathrm{HR}=1.5, p=$ 0.01 ), were independently significant poor prognostic factors, and the most recent two time-periods, the ablation period $2011-2014(\mathrm{HR}=0.7, p<0.01)$ and the ablation period 2015-2018 ( $\mathrm{HR}=0.4, p<0.001)$, were protective factors (online suppl. Table S8, online suppl. Fig. S4). 

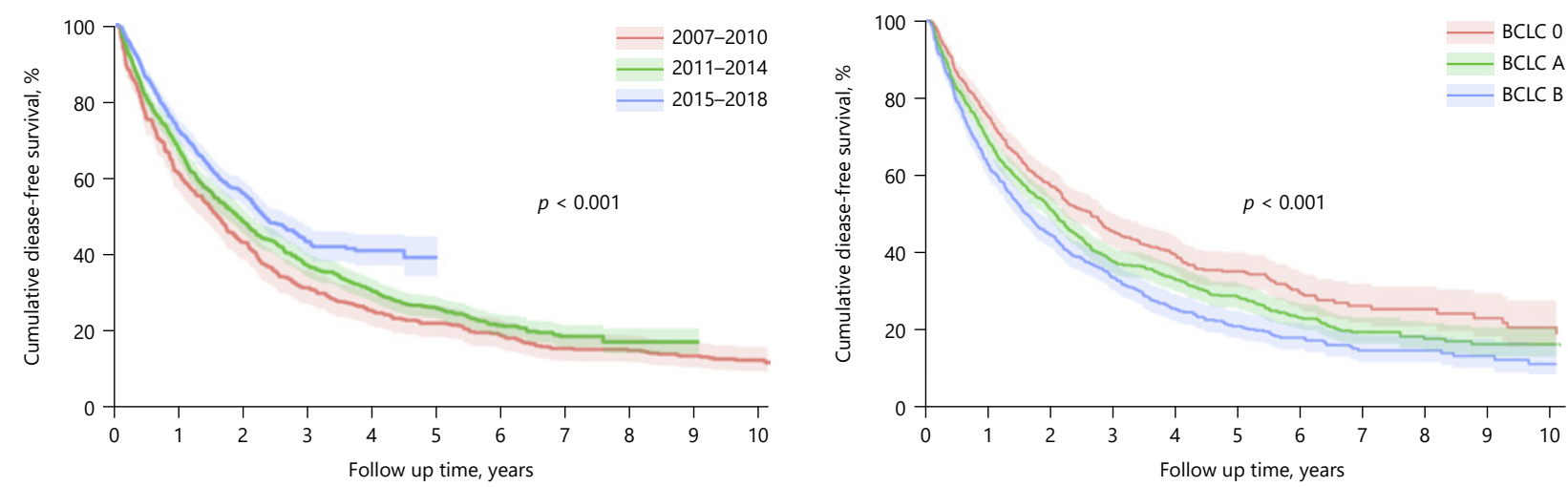

No.at risk
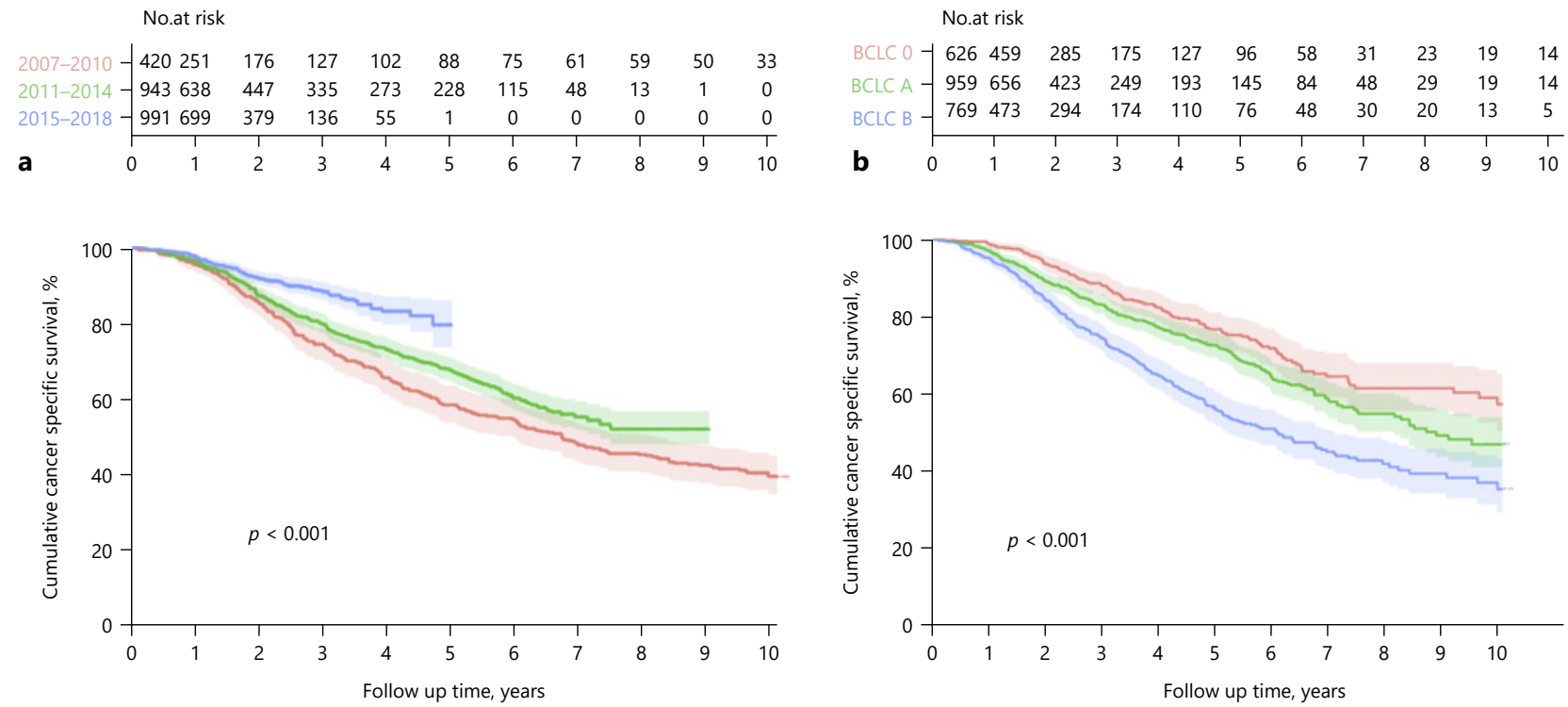

No.at risk
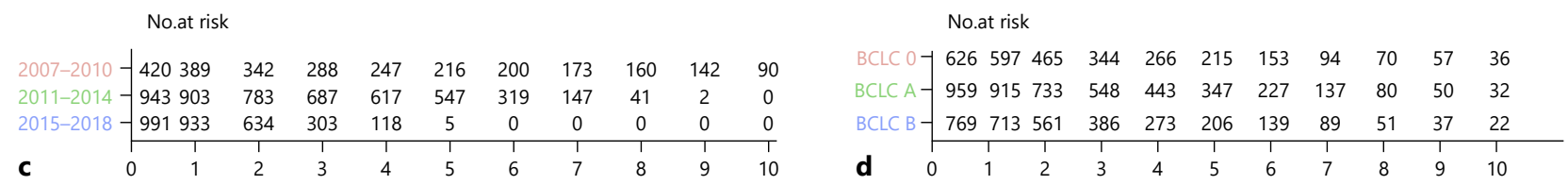

Fig. 4. a Analysis of DFS. $\mathbf{b}$ DFS of BCLC stage 0 , A, and B patients. c CSS. $\mathbf{d}$ CSS of BCLC stage 0 , A, and B patients stratified by time-period of MWA according to the Kaplan-Meier method. DFS, disease-free survival; CSS, cancer-specific survival; MWA, microwave ablation.

The results verified that the ablation period was not a competitive risk for dying from HCC. ER, LR, and NR shared different risk factors, which might be the reason for the different occurrence rate of the three types of recurrence (online suppl. Table S15).

\section{Major Complications}

A total of 122 major complications (Clavien Grade III$\mathrm{V}$ ) were encountered within 1 month after MWA (Ta- ble 4). The incidence rates of major complications per patient and procedure were $5.2 \%(122 / 2,354)$ and $3.0 \%$ $(122 / 4,051)$, respectively. The treatment mortality decreased, while other major complications showed no improvement with time-period progression. Minor complications are summarized in online supplementary Table S16. 
Table 3. Cox proportional hazard regression analyses of the association between all-cause death and recurrence

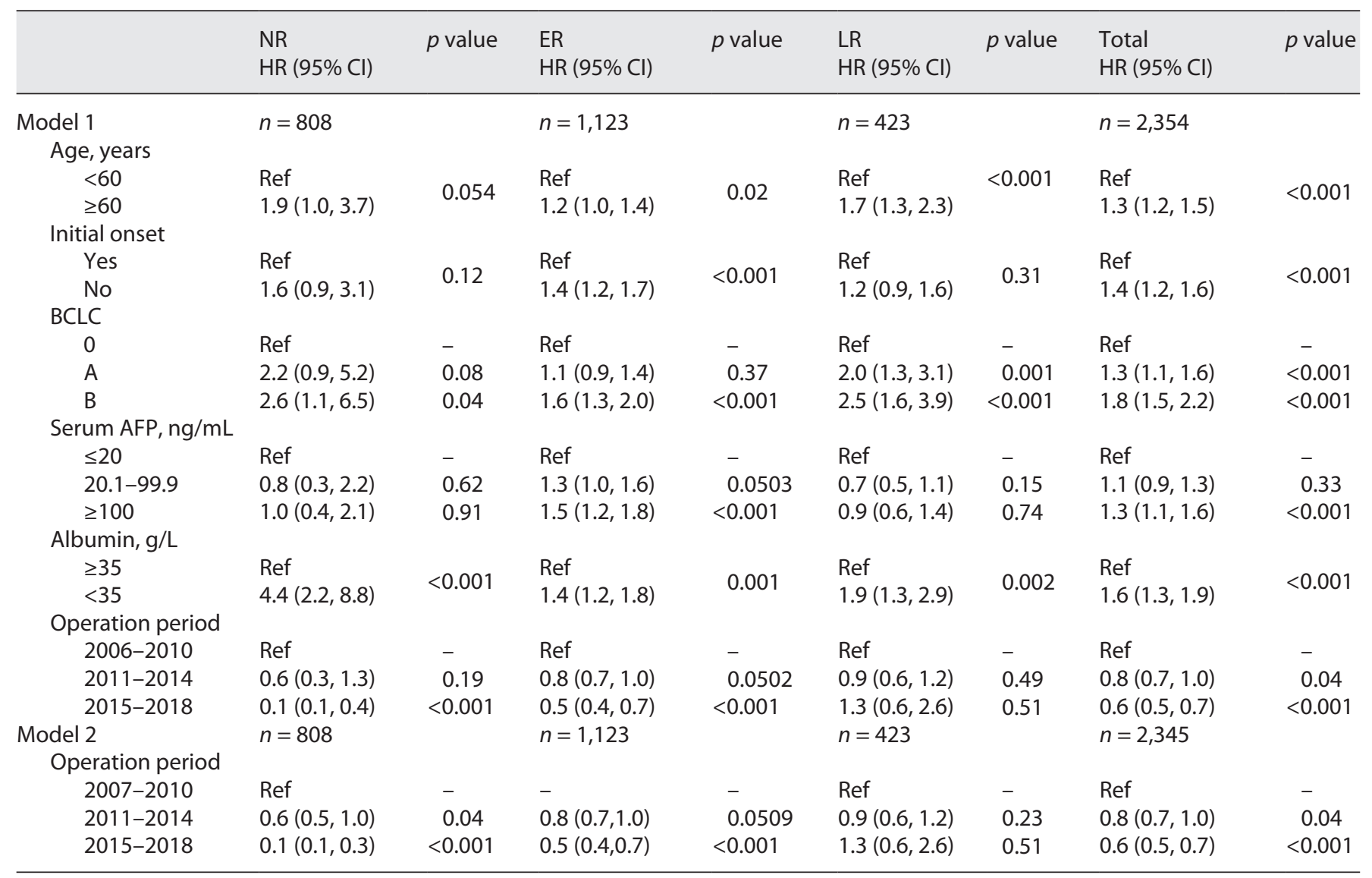

BCLC, Barcelona Clinic Liver Cancer stage; Model 1 being unadjusted; Model 2 adjusting model 1 for potential prognostic factors including age, initial onset, BCLC stage, serum AFP level, and albumin.

Table 4. Major complications during and after all patients treated by MWA

\begin{tabular}{llllll}
\hline $\begin{array}{l}\text { Clavien } \\
\text { Grade }\end{array}$ & Complication & $\begin{array}{l}\text { Total } \\
(n=122)\end{array}$ & $\begin{array}{l}2007-2010 \\
(n=27)\end{array}$ & $\begin{array}{l}2011-2014 \\
(n=42)\end{array}$ & $\begin{array}{l}2015-2018 \\
(n=53)\end{array}$ \\
\hline $\mathrm{V}$ & Deaths & $5(0.21)$ & $2(0.48)$ & $2(0.21)$ & $1(0.10)$ \\
\hline $\mathrm{IVb}$ & Respiratory failure & $1(0.04)$ & $0(0.00)$ & $0(0.00)$ & $1(0.10)$ \\
\hline $\mathrm{IIIb}$ & Colon perforation & $5(0.21)$ & $2(0.48)$ & $1(0.11)$ & $2(0.20)$ \\
& Needle tract & $5(0.21)$ & $2(0.48)$ & $2(0.21)$ & $1(0.10)$ \\
& Severe bleeding & $4(0.17)$ & $1(0.24)$ & $1(0.11)$ & $2(0.20)$ \\
& Respiratory failure & $1(0.04)$ & $0(0.00)$ & $0(0.00)$ & $1(0.10)$ \\
\hline IIIa & Needle tract & $25(1.06)$ & $5(1.19)$ & $10(1.06)$ & $10(1.01)$ \\
& Pleural effusion & $62(2.63)$ & $12(2.86)$ & $23(2.44)$ & $27(2.72)$ \\
& Ablation zone infection & $11(0.47)$ & $3(0.71)$ & $2(0.21)$ & $6(0.61)$ \\
& Cholecyst perforation & $1(0.04)$ & $0(0.00)$ & $0(0.00)$ & $1(0.10)$ \\
& Severe bleeding & $2(0.08)$ & $0(0.00)$ & $1(0.11)$ & $1(0.10)$ \\
\hline
\end{tabular}

Data are numbers of patients with percentages in parentheses for categorical variables. 


\section{Discussion}

A variety of studies on MWA of HCC have been reported in recent decades from the viewpoint that this minimally invasive modality can be applied to patients who are intolerant to surgery and can be conducted repeatedly for disease recurrence in the same patients $[8,26]$. However, results on the large database evaluating more than 10 years of technique efficacy are absent due to its relatively short history of clinical applications, despite several studies reporting the 5 -year outcomes $[8-10,26,27]$. Based on previously accumulated clinical experiences, we organized a multicentric study on a 12-year consecutive case series from 5 tertiary referral and high-volume centers. This study had two primary aims: 1 . to investigate the 10year therapeutic advancement of the percutaneous MWA technique for treating HCC during 3 periods; 2 . to ascertain whether survival and recurrence benefit has been achieved for many subjects of MWA for HCC with BCLC stage $\mathrm{B}$, risk location, and rapid progression, by analyzing valuable data on tumor progression, patient survival, and variables relevant to these outcomes and complications. To our knowledge, this study is the first to document the largest sample of ablation treatment for HCC with the 10year outcome (online suppl. Table S17). Although the present results were based on heterogeneous nationwide data, we believe that analyzing a large multicentric cohort of over 2,300 patients can elicit reliable conclusions.

On a total of 2,354 HCC patients, 4,051 percutaneous MWA sessions were performed, showing that MWA has an acceptable antitumor effect. The vast majority (97.5\%) of tumors were diagnosed as completely ablated by contrastenhanced imaging such as TS after MWA, including both the first MWA and iterative MWA for recurrence. Although the TS rate differed with increasing tumor size, there was no distinct drop-off in the effectiveness. Especially for 3.1-5.0-cm HCCs, ablation sessions gradually decreased, and TS gradually increased over time, reflecting the interventional radiologists' skill in mastering the MWA technique. Apart from TS, the LTP is another crucial index to evaluate the technological level on complete ablation performance, which has been reported to be related to improved survival of HCC patients [28-30]. The favorable TS and LTP rates observed in this study were likely attributed to the repeated MWA procedures generally performed within 3 days after MWA when the residual tumor was detected or insufficient ablation margin was observed by contrast-enhanced imaging (US, magnetic resonance imaging, or computed tomography). Complete local control for tumors might have contributed to the improved survival re-

Microwave Ablation of Hepatocellular Carcinoma sults in the study, even when including $32.7 \%$ of BCLC stage $\mathrm{B}$ cases and $34.7 \%$ of patients with high-risk comorbidities for resection. However, larger tumor size $(>3.0 \mathrm{~cm})$ and perivascular location remained the major challenges for LTP improvement. Reasonable spatial distribution of thermal field to cover the large-size tumor and reduction of heat sink's adverse effect are major but not the only factors that accounted for the TS and LTP of MWA. Continuous advancements along the direction of these strategies may enhance the prognosis.

MWA for HCC has been verified as a safe and effective procedure over the past decade. Improving the survival results has become the next important target in the MWA management of HCC. Frequent recurrence is the predicament for HCC treatment, and HCC progression was the leading cause of death in our study. Most recurrences were not LTP and EM but IDM after MWA. The decrease of IDM and EM over the three periods manifested their contribution to gradually increasing HCC-related survival. The current study shows that the prognosis of BCLC stage 0/A HCC and the OS, DFS, and CSS for BCLC stage BHCC improved over the past decade. Although there was no clear adjuvant therapy after MWA to reduce recurrence, it is noteworthy that periodic follow-up to observe most recurrences at limited stage was a crucial factor in improving prognosis. Iterative MWA, due to its minimal invasion and validity, could provide patients with recurrent disease the potential opportunity to eradicate the tumor completely if the tumor is detected early. In our study, MWA was performed for recurrence in $77.1 \%$ of cases, even up to 11 procedures of MWA in the same patient, reflecting the special advantages of repeatability for ablation.

Our cohort documented a clear ascending rate of OS, DFS, and CSS over the three periods as expected. The independent risk significance of tumor stage BCLC B and not initial HCC at MWA was shared by three survivals, which strongly stresses the importance of early treatment as the determinant of prognosis [31]. However, the independent prognostic significance of the time-period of MWA indicates that improvement of the therapeutic technique contributed to the amelioration of survival; specifically, favorable OS and DFS advances over time were observed in ER patients, who have relatively strong tumor invasive potential, accounted for $47.7 \%$ of relapsed HCC cases, and have been associated with poor survival. This is likely owing to the thermal efficiency advantage of MWA, as well as the rapid development of the ablation technique, including artificial fluid infusion, three-dimensional ablation plan, evaluation, and multi-model image fusion navigation $[11,23,32]$, which promote the 
complete necrosis of target lesions, even if there is rapid disease recurrence after MWA. In addition, the contribution of palliative treatment options such as transarterial chemoembolization, radiation therapy, and systemic sorafenib therapy in combination with MWA for some patients experiencing late-stage recurrence and frequent recurrence cannot be ignored. Therefore, patients benefit from early tumor detection for recurrent HCC to access MWA and multiple treatment modalities. Over the past decade, even though other treatment modalities could not achieve comparable survival with iterative MWA in recurrent patients, the further prolonged survival of HCC patients after combined treatments is still expected once the efficacy of combining the target and immunotherapy adjuvant therapies is fully established and recommended for rational use after MWA.

MWA is a safe procedure. Although 816 (34.7\%) patients treated with MWA in this study were at high risk for resection for insufficient hepatic functional reserve or other comorbidities, major complications occurred in only $2.2 \%$ of the patients. Furthermore, iterative MWA is also a safe and well-tolerated option for patients. Therefore, MWA provides a chance for minimally invasive inactivation of the tumor and liver function protection after repeated ablation in the same patient. This was especially true in the 348 patients who received more than three treatments or even when the patient underwent 11 MWA treatments. Therefore, it may be more beneficial than surgery with limited repeated resection chance and relatively high morbidity, particularly because laparoscopic hepatic resection has a major complication rate of $2.3-9.8 \%$, as reported in recent studies [17, 33, 34].

Some additional limitations should be mentioned. This large-scale study, which was based on a multicenter database, provides a strong interpretation of the real-world effectiveness of US-guided percutaneous MWA treatment for HCC. However, the generalized interpretation of our results toward the low-volume centers, or even community hospitals with less experience, is not clear. Moreover, the real-world data included initial and recurrent HCC patients. Although the impact of prior treatments was still in dispute for the ablation effect, the inferior OS of recurrent HCC compared to the initial disease could potentially drag down the long-term survival results in our study. The detailed prognosis difference between the two groups is worth exploring. In addition, tumor biology and differentiation are relevant factors when observing tumor recurrence. The technique efficacy is an important indicator to evaluate the "adequate" ablation of the tumor and reflect the ablation skills. However, it is difficult to address their possible relationship with MWA prognosis for the missing variables in the retrospective study. A prospective follow-up study with a worldwide representative database is required to quantitatively assess the contribution of this technique for the HCC treatment.

In conclusion, this 12-year follow-up report of the multicenter cohort study provides valuable evidence with the longest follow-up data yet for HCC patients treated with percutaneous MWA. It showed a significant improvement in both OS and DFS results over the past decade due to advances in the early detection and ablation management of HCC. Furthermore, improving longterm survival after MWA of HCC depends on research efforts to develop effective local tumor control techniques and adjuvant therapy in the future.

\section{Statement of Ethics}

This multicenter study was performed in accordance with the ethical guidelines of the 1975 Declaration of Helsinki. Written informed consent for the procedure was obtained from each enrolled patient, and the treatment was approved by the Institutional Review Board of each institution, while the paper is exempt from Ethical Committee approval due to its retrospective nature.

\section{Conflict of Interest Statement}

The authors have no conflicts of interest to declare.

\section{Funding Sources}

The study was not supported by any research funding.

\section{Author Contributions}

Dr Liang Ping and Yu Jie: full access to all of the data in the study and responsible for the integrity and the accuracy of the data analysis. Liang Ping and Yu Jie: study concept and design. Liang Ping, Yu Jie, Yu Xiao-ling, Cheng Zhi-gang, Han Zhi-yu, Liu Fangyi, Zheng Rong-qin, Cheng Wen, Wei Qiang, Yu Song-yuan, Li Qin-ying, He Guang-zhi, and Luo: acquisition of data. Liang Ping, Yu Jie, and Luo Yan-chun: acquisition of data. Yu Jie: drafting of the manuscript. Yu Jie and Liang Ping: critical revision of the manuscript for important intellectual content.

\section{Data Availability Statement}

The research data are not publicly available on ethical grounds. However, inquiries regarding all data analyzed in this study can be directed to the corresponding author. 


\section{References}

1 Siegel RL, Miller KD, Jemal A. Cancer statistics, 2019. CA Cancer J Clin. 2019 Jan;69(1): 7-34.

2 Bruix J, Gores GJ, Mazzaferro V. Hepatocellular carcinoma: clinical frontiers and perspectives. Gut. 2014 May;63(5):844-55.

3 Lencioni R. Loco-regional treatment of hepatocellular carcinoma in the era of molecular targeted therapies. Oncology. 2010 Aug;78 Suppl 1:107-12.

4 Seki T, Wakabayashi M, Nakagawa T, Itho T, Shiro T, Kunieda K, et al. Ultrasonically guided percutaneous microwave coagulation therapy for small hepatocellular carcinoma. Cancer. 1994 Aug 1;74(3):817-25.

5 Simon CJ, Dupuy DE, Mayo-Smith WW. Microwave ablation: principles and applications Radiographics. 2005 Oct;25 Suppl 1:S69-83.

6 Brace CL. Radiofrequency and microwave ablation of the liver, lung, kidney, and bone: what are the differences? Curr Probl Diagn Radiol. 2009 May-Jun;38(3):135-43.

7 Yu J, Liang P, Yu X, Liu F, Chen L, Wang Y. A comparison of microwave ablation and bipolar radiofrequency ablation both with an internally cooled probe: results in ex vivo and in vivo porcine livers. Eur J Radiol. 2011 Jul; 79(1):124-30

8 Yu J, Yu XL, Han ZY, Cheng ZG, Liu FY, Zhai $\mathrm{HY}$, et al. Percutaneous cooled-probe microwave versus radiofrequency ablation in earlystage hepatocellular carcinoma: a phase III randomised controlled trial. Gut. 2017 Jun; 66(6):1172-3.

9 Vietti Violi N, Duran R, Guiu B, Cercueil JP, Aubé C, Digklia A, et al. Efficacy of microwave ablation versus radiofrequency ablation for the treatment of hepatocellular carcinoma in patients with chronic liver disease: a randomised controlled phase 2 trial. Lancet Gastroenterol Hepatol. 2018 May;3(5):317-25.

10 Forner A, Reig M, Bruix J. Hepatocellular carcinoma. Lancet. 2018 Mar 31;391(10127) 1301-14.

11 Zhang M, Liang P, Cheng ZG, Yu XL, Han $\mathrm{ZY}, \mathrm{Yu}$ J. Efficacy and safety of artificial ascites in assisting percutaneous microwave ablation of hepatic tumours adjacent to the gastrointestinal tract. Int J Hyperthermia. 2014 Mar;30(2):134-41.

12 Huang H, Liang P, Yu XL, Cheng ZG, Han $\mathrm{ZY}$, Yu J, et al. Safety assessment and therapeutic efficacy of percutaneous microwave ablation therapy combined with percutaneous ethanol injection for hepatocellular carcinoma adjacent to the gallbladder. Int J Hyperthermia. 2015 Feb;31(1):40-7.

13 Medhat E, Abdel Aziz A, Nabeel M, Elbaz T, Zakaria Z, Shousha H, et al. Value of microwave ablation in treatment of large lesions of hepatocellular carcinoma. J Dig Dis. 2015 Aug;16(8):456-63.

14 Sun AX, Cheng ZL, Wu PP, Sheng YH, Qu XJ, $\mathrm{Lu} \mathrm{W}$, et al. Clinical outcome of mediumsized hepatocellular carcinoma treated with microwave ablation. World J Gastroenterol. 2015 Mar 14;21(10):2997-3004.

15 Liang P, Dong B, Yu X, Yu D, Wang Y, Feng $\mathrm{L}$, et al. Prognostic factors for survival in patients with hepatocellular carcinoma after percutaneous microwave ablation. Radiology. 2005 Apr;235(1):299-307.

16 Liang P, Yu J, Yu XL, Wang XH, Wei Q, Yu SY, et al. Percutaneous cooled-tip microwave ablation under ultrasound guidance for primary liver cancer: a multicentre analysis of 1363 treatment-naive lesions in 1007 patients in China. Gut. 2012 Jul;61(7):1100-1.

17 Li W, Zhou X, Huang Z, Zhang K, Luo X, Zhong J, et al. Short-term and long-term outcomes of laparoscopic hepatectomy, microwave ablation, and open hepatectomy for small hepatocellular carcinoma: a 5-year experience in a single center. Hepatol Res. 2017 Jun;47(7):650-7.

18 Xu Y, Shen Q, Liu P, Xu Z, Wu P, Lu Z, et al. Microwave ablation for the treatment of hepatocellular carcinoma that met up-to-seven criteria: feasibility, local efficacy and longterm outcomes. Eur Radiol. 2017 Sep;27(9): 3877-87.

19 Leoni S, Piscaglia F, Serio I, Terzi E, Pettinari I, Croci L, et al. Adherence to AASLD guidelines for the treatment of hepatocellular carcinoma in clinical practice: experience of the bologna liver oncology group. Dig Liver Dis. 2014 Jun;46(6):549-55.

20 EASL Clinical Practice Guidelines. EASL clinical practice guidelines: Management of hepatocellular carcinoma. J Hepatol. 2018 Jul; 69(1):182-236

21 Heimbach JK, Kulik LM, Finn RS, Sirlin CB, Abecassis MM, Roberts LR, et al. AASLD guidelines for the treatment of hepatocellular carcinoma. Hepatology. 2018 Jan;67(1):35880.

22 Liang P, Yu J, Lu MD, Dong BW, Yu XL, Zhou $\mathrm{XD}$, et al. Practice guidelines for ultrasoundguided percutaneous microwave ablation for hepatic malignancy. World J Gastroenterol. 2013 Sep 7;19(33):5430-8.

23 Zhang D, Liang P, Yu X, Cheng Z, Han Z, Yu $J$, et al. The value of artificial pleural effusion for percutaneous microwave ablation of liver tumour in the hepatic dome: a retrospective case-control study. Int J Hyperthermia. 2013 Nov;29(7):663-70.

24 Ahmed M, Solbiati L, Brace CL, Breen DJ, Callstrom MR, Charboneau JW, et al. Image-guided tumor ablation: standardization of terminology and reporting criteria: a 10 year update. Radiology. 2014 Oct;273(1): 241-60.

25 Dindo D, Demartines N, Clavien PA. Classification of surgical complications: a new proposal with evaluation in a cohort of $6336 \mathrm{pa}-$ tients and results of a survey. Ann Surg. 2004 Aug;240(2):205-13.

26 Beermann M, Lindeberg J, Engstrand J, Galmén K, Karlgren S, Stillström D, et al. 1000 consecutive ablation sessions in the era of computer assisted image guidance: Lessons learned. Eur J Radiol open. 2019;6:1-8.

27 Kaibori M, Yoshii K, Hasegawa K, Ogawa A, Kubo S, Tateishi R, et al. Treatment optimization for hepatocellular carcinoma in elderly patients in a Japanese Nationwide Cohort. Ann Surg. 2019 Jul;270(1):121-30.

28 Sala M, Llovet JM, Vilana R, Bianchi L, Solé $\mathrm{M}$, Ayuso C, et al. Initial response to percutaneous ablation predicts survival in patients with hepatocellular carcinoma. Hepatology. 2004 Dec;40(6):1352-60.

29 Yin XY, Xie XY, Lu MD, Xu HX, Xu ZF, Kuang M, et al. Percutaneous thermal ablation of medium and large hepatocellular carcinoma: long-term outcome and prognostic factors. Cancer. 2009 May 1;115(9):1914-23.

30 Sparchez Z, Mocan T, Radu P, Mocan LP, Sparchez M, Leucuta DC, et al. Prognostic factors after percutaneous radiofrequency ablation in the treatment of hepatocellular carcinoma. Impact of incomplete ablation on recurrence and overall survival rates. J Gastrointestin Liver Dis. 2018 Dec;27(4):399-407.

31 De Toni EN, Schlesinger-Raab A, Fuchs M, Schepp W, Ehmer U, Geisler F, et al. Age independent survival benefit for patients with hepatocellular carcinoma (HCC) without metastases at diagnosis: a population-based study. Gut. 2020 Jan;69(1):168-76.

32 Zhang D, Liang W, Zhang M, Liang P, Gu Y, Kuang M, et al. Multiple antenna placement in microwave ablation assisted by a three-dimensional fusion image navigation system for hepatocellular carcinoma. Int J Hyperthermia. 2019 Jan 1;35(1):122-32.

33 Song J, Wang Y, Ma K, Zheng S, Bie P, Xia F, et al. Laparoscopic hepatectomy versus radiofrequency ablation for minimally invasive treatment of single, small hepatocellular carcinomas. Surg Endosc. 2016 Oct;30(10): 4249-57.

34 Chong CC, Lee KF, Chu CM, Chan AW, Yu SC, Lai PB. Laparoscopic hepatectomy (with or without robotic assistance) versus radiofrequency ablation as a minimally invasive treatment for very early-stage or early-stage hepatocellular carcinoma. Dig Surg. 2020;37(1): 65-71. 